\title{
Photography as a Medium for Urban Regeneration. A Case Study on the University District of Pescara, Italy ${ }^{\dagger}$
}

\author{
Antonella Salucci \\ Department of Architecture, University ‘Gabriele d'Annunzio' Chieti-Pescara, Viale Pindaro, 65127 Pescara, \\ Italy; antonella.salucci@unich.it; \\ + Presented at the International and interdisciplinary conference IMMAGINI? Image and Imagination \\ between representation, communication, education and psychology, Brixen, Italy, 27-28 November 2017. \\ Published: 21 November 2017
}

\begin{abstract}
This paper proposes a summary of the results of an ongoing research on the Adriatic city of Pescara, specifically referring to its university district. The study seeks to investigate urban spaces, taking advantage of the representation made possible through mobile-photography, a mode of observation that is increasingly present in current orientations of the culture of the urban project. A way that reflects the will to adhere to the recent guidelines of the MiBACT that has recently decreed the States General for Photography, in order to "protect, enhance and promote" Italian photography as historical heritage and a contemporary language.
\end{abstract}

Keywords: photography; urban surveying; ephemeral heritage; university district; Instagram

\section{Introduction}

This paper proposes a summary of the results of a research campaign on the Adriatic city of Pescara, specifically referring to its university district and aiming to explore some of its distinguishing features. The study seeks to investigate these urban spaces, taking advantage of the representation made possible through the medium of photography, a mode of observation that is increasingly present in current orientations of the culture of the urban project. This contribution reflects specifically the desire to preserve and pass on the shared memory of a narrative by means of mobile-photography and deal with a medium that has never been so popular as now.

The main lines of investigation, consequential and interrelated, are accompanied by depictions of different points of view, that tell us about shared urban spaces. A summary of the city's chromatic expression is proposed, enabling you to map the texture and colour of a complex, uneven territory that is continually-transforming and extremely interesting. On the one hand, there are a selection of images, captured whilst passing through the historic part of the city; on the other hand there is a story told through photographs of the urban, university spaces, the Polo Pindaro.

The coastal city of Pescara was founded in 1927, unifying of two municipalities established on the river of the same name. The city presents many conflicting aspects that are juxtaposed as nonexhaustive colour notes, - think of Ettore Sottsass's 'Pictures from a window' - from the notebook of a traveller who is passing through [1]. The research is aimed at observing the architectural spaces of the university district through a series of workshops for architecture students led by the writer, dedicated to surveying and taking photos of architecture. The collective spaces of movement, rest, entertainment, meeting, socialising, waiting, and relaxing, are fixed on the sensor by the same users of those spaces, witnessing a collective way of living. This result is a visual system composed of fragments and impressions that highlight the habits and aesthetic tendencies of the main 'inhabitants' of the university district. The adopted methodologies can be summarised using two main processing spheres: on the one hand, the survey and representation of the main axis of the university district, 
Viale Pindaro; on the other hand, the process of photographic analysis and reflection of the collective urban spaces in the university district.

In this scenario, the research aims to contribute, through unusual points of view, to the documentation of the unpublished aspects of an Italian university district (Figure 1).

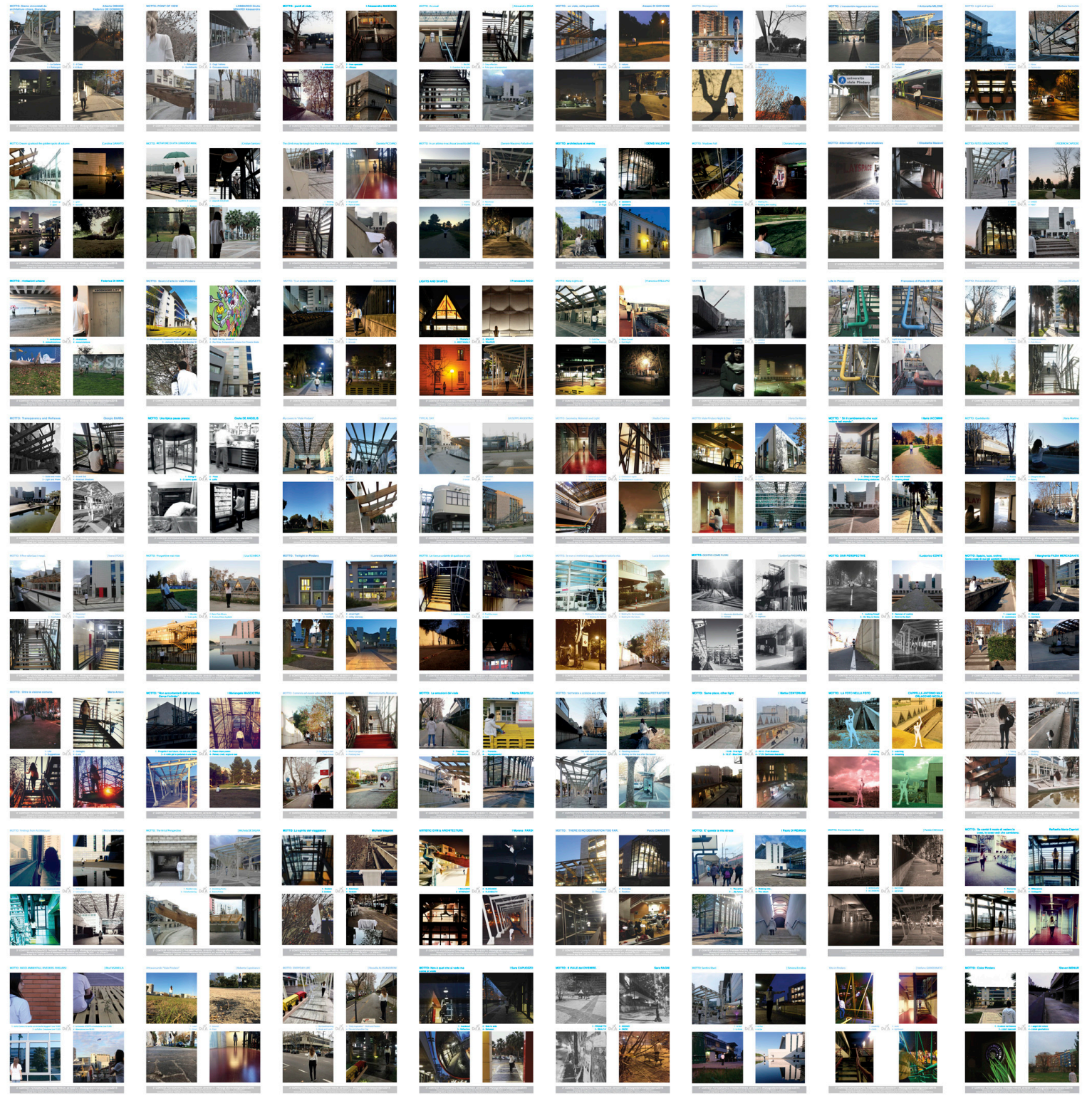

Figure 1. Pescara University District. \#theinbetween, Photographic survey project. Available online: http://www.allievivialepindaro.wordpress.com; a mobile-photography contest for Instagram @allievivialepindaro, \#fotografarevialeindaro2016.

It has the dual objective of detecting the common traits of different spaces in the contemporary city and affirming some of the distinguishing features of this young and complex foundation city. It is useful to highlight the fact that the MiBACT Ministry of Heritage, Culture and Tourism decreed the States General for Photography, on 6 April 2017, in order to: "Protect, enhance and promote photography in Italy as historical heritage and a contemporary language, storage medium, means of expression and understanding of reality, useful for fostering inclusion and increasing individual critical awareness on the part of citizens. The aim is to define a development plan aimed at adapting public actions to the technical and economic changes in the industry and create new opportunities, nationally and internationally, for Italian photography" [2,3]. 


\section{Drawing Pescara's University District with the Mobile-Photography}

Like many New Cities created in Italy in the Twentieth Century, and many other examples of urban settlements built in the Fascist period, interpreting the city allows us to detect anomalies that can be attributed to the process of urban planning linked to the utopian sphere, calling for a type of reflection that has to do with its immediate realization.

Organised in a north-east-south-west layout, like all linear cities on the Adriatic coast, Pescara is marked by a continuous urbanisation that has been summarised by Livio Sacchi: "a true linear system, made up of medium-small and very small coastal cities almost all of which have merged into each other. (...) on the Adriatic coast, everything seems to cross over a narrow 'corridor' that struggles to house urban, industrial and tourist areas, as well as a considerable amount of infrastructure (...) the flat space along the coast is essentially very slim, enclosed by the sea to the northeast and the mountains to the southwest. In the section in Pescara, there are only a few kilometres separating the sea from the ridge of the highest mountains on the Italian peninsula, such as Maiella and Gran Sasso. (...) This is a widespread urban system that, whether we like it or not, definitively puts our historical notion of the city in crisis" [4].

Dominated for centuries by the Carlo V's polygonal fortress to guard the mouth of the river that marks the boundary between the two provinces of the Abruzzi, - Abruzzo Ultra to the north and Citra to the south - the new Pescara, in the province of Chieti, was founded in 1927 by merging the rural centre with Castellammare Adriatico on the other side of the river, which belonged to the province of Teramo.

The birth of modern Pescara is linked to the growing importance of the strategic role of settlements along the Adriatic coast, set in a system of connected national infrastructure, joining the Adriatic line with the road across the Apennines to Rome.

The arrival of the railway brought 'new functions' to the coast linked to the use of the coast as a seaside destination, as Antonello Alici has pointed out: "in under a century, the lives and signs of many cities pass by and settle down. The city of pioneers who arrived on the railway, the city of tourism and swimming in the sea (...) the garden city with the wide streets lined with slender young trees and two-story houses and villas, the city of the palaces of power that interpret the rhetoric of the Fascist regime, the city of cars home to the Coppa Acerbo circuit (...) the city which was swept away and disfigured by the American bombs and the German mines. The city that is still green and measured by the houses for the homeless and the popular neighbourhoods, the city of elegant apartment blocks (...) the city that grows dense without order or decorum until the coast and the hills are saturated" [5].

A complexity that persists but that has assumed a precise direction that we find in a piece of writing from a decade ago by Alberto Clementi, who was at that time the head of the Faculty of Architecture: "even a few years ago, the types of architecture in a rapidly changing city such as Pescara had little in common with works produced by the university. On the one hand, there is a construction industry that is voracious and unbridled like a foam that is as porous as it is dense. On the other hand, there is a school of architecture reaching out to the values of contemporaneity in the new state, explored through the forms of the infinite city on the Adriatic coast and the accumulation of low-quality infrastructure (...) two worlds have begun to come closer (...) helping to regenerate the public spaces and voids in the city centre...) giving impetus to new centres in semi-peripheral areas within the consolidated city. Particularly in a marginal area, where the d'Annunzio University was pioneeringly established over twenty years ago, under the guidance of a controversial program agreement they are focusing on important public functions, such as the newly completed judicial area and other profitable private real estate initiatives, aimed at capturing the strong positional value acquired by this strategic area for the future of the city" [6] (Figure 2).

The university district, the University of Annunzio's Polo Pindaro, is located in the southern quadrant of the city, near the Pineta Dannunziana, established along the stretch that leads to the sea Viale Pindaro is an approximately $700-\mathrm{m}$ long axis where various educational and research Department buildings of the 'Gabriele d'Annunzio' University in Chieti-Pescara are situated, including Architecture, Engineering, Economics, and Languages. 


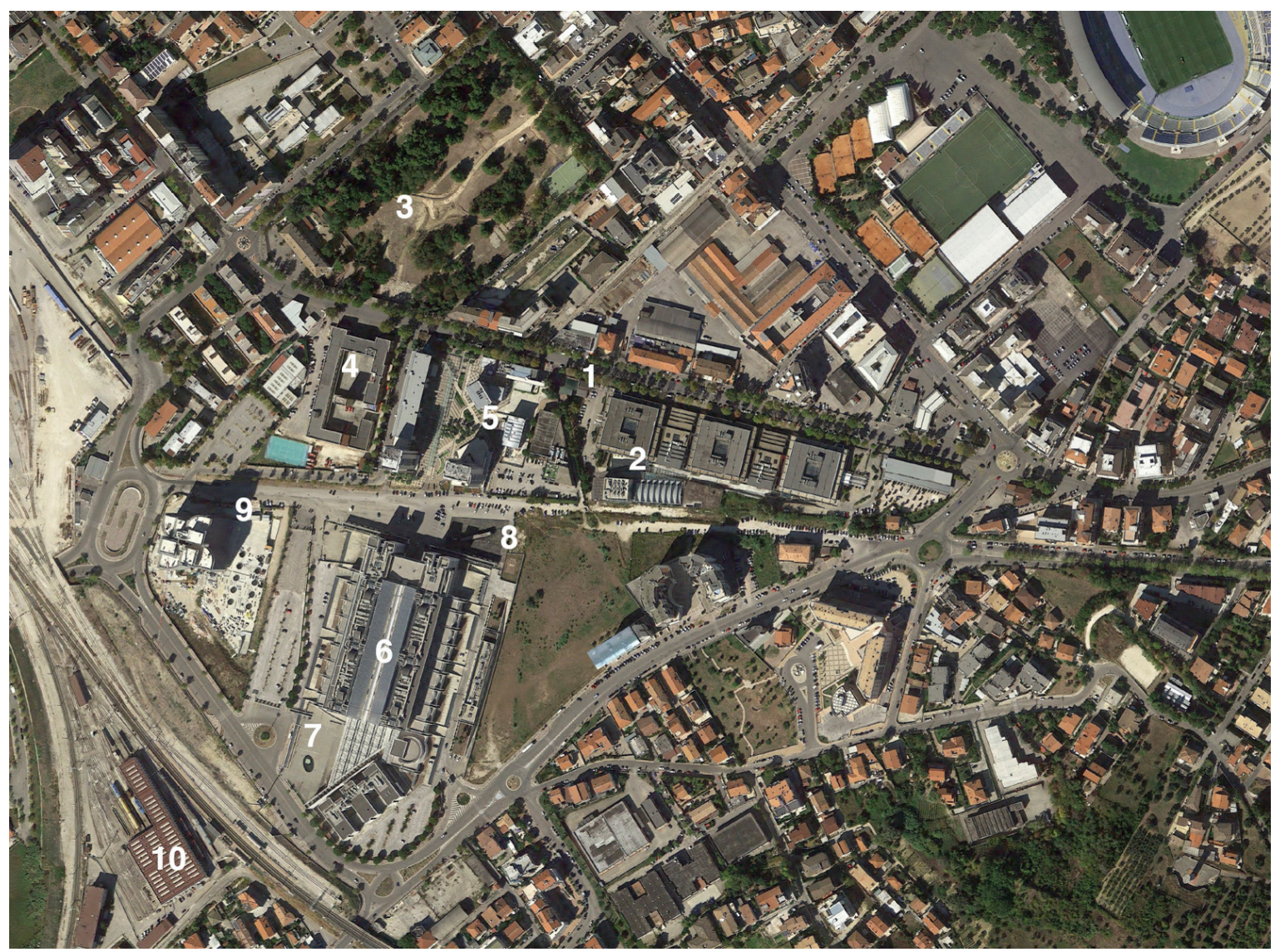

Figure 2. Pescara. Viale Pindaro. University Campus of Pescara. Gabriele d'Annunzio University. Satellite view, Google Maps, 2015. Highlights (1) the urban axis of Viale Pindaro, the tree-lined avenue that borders the university spaces; (2) the blocks of university buildings: Architecture, Foreign Languages and Literature, Economics and Management Sciences; The new Micara classroom; The Administrative Offices; (3) the Ex Caserma di Cocco Park; (4) the Fire Brigade; (5) Piazza Accademia, Studio SAUD project (2002-2007); (6) the Court of Pescara, project by Franco Agresta and Giulio Fioravanti (2005); (7) The Courthouse's round fountain from the project by Ettore Spalletti (2004); (8) Monumento Caduti di Nassirya, designed by Giangiacomo D'Ardia (2005); (9) Residential tower building “Torre OperA", designed by Mario Botta (2009-2011); (10) Tribunale Railway Station.

The so called Polo Pindaro is a complex urban area where the dynamics of the everyday activities of the students of the school of Architecture take place (Figures 2 and 3a,b). A type of boulevard that is home to several spectacular specimens of sycamore trees, Viale Pindaro represents one of the stretches of a larger area of around 30 hectares with interesting features. Among these features we will observe: the position near Pineta Dannunziana, the city's "green lung"; the presence of the exCaserma "Di Cocco" park; the area adjacent to the new Piazza Accademia; the proximity of Pescara Tribunale railway station to the railway line and the monolithic spaces of the Court of Pescara, which are home to two important installations - "Omaggio a Nassyria" by the architect Giangiacomo D'Ardia (2005) and the "Disco" fountain by the artist Ettore Spalletti (2004).

With regard to this work, as far as this discussion is concerned, it seems appropriate to point out what has been said by the artist Ettore Spalletti-he has recently received the Laurea Honoris Causa from the School of Architecture in May 2017-thought of this sculpture specifically in terms of 'light and colour', he defines it as a black disc, a mirror of water, that: "is there to remind us of Pescara's light, articulating each hour through its reflection, showing us different pictures and colours at different hours of the day. When the light is going down, it takes on an elliptical shape until it is illuminated at night" [7]. 


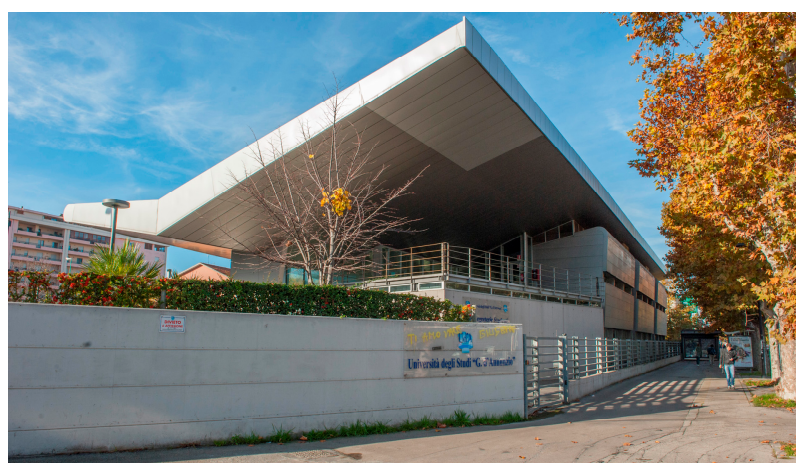

(a)

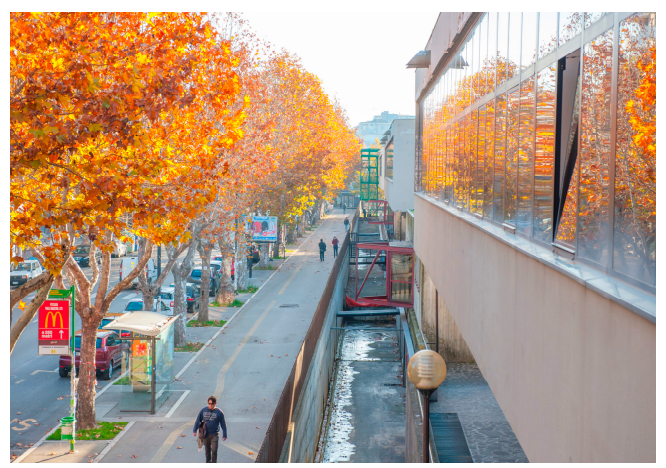

(b)

Figure 3. (a,b)-Pescara. Daytime. Viale Pindaro. (Photographs by Antonella Salucci).

The photography workshop '\#theinbetween', now in its fourth edition, is a seminar organised for architects enrolled in the first and second year; it is aimed at awareness, observation, and prefiguration of the architecture and the environment and it is built through the medium of mobilephotography (Figures 1, 4 and 5).

MOTTO: Geometry, Materials and Light

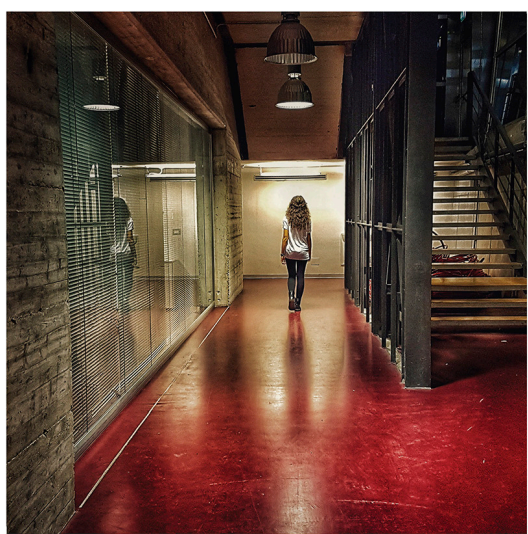

- Materiale e contrasto 3 - Struttura e regolarit

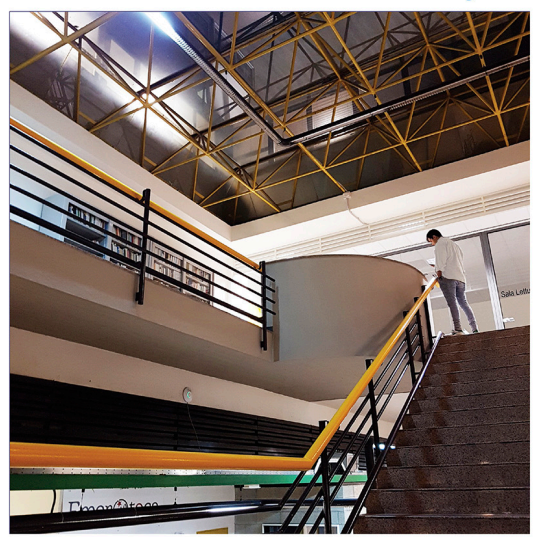

| Hadla Chahine

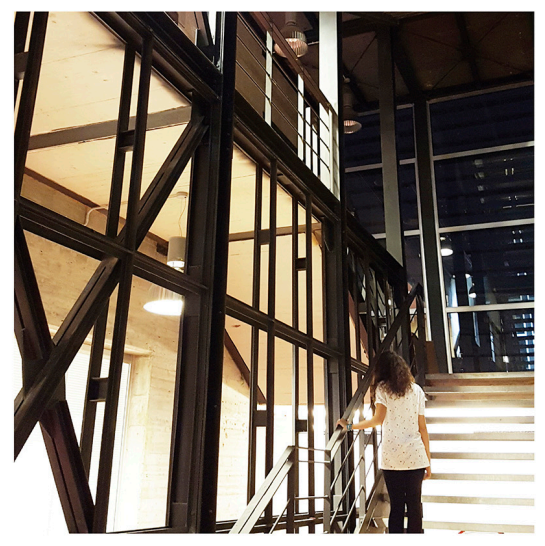

2- Chiarezza e rigore

4 - Dimensione e modernità

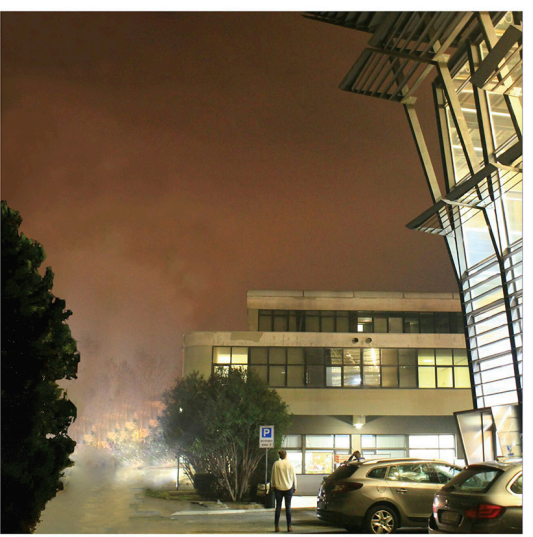

$3^{\circ}$ CONTEST FOTOGRAFICO THEINBETWEEN 2016/2017 I \#fotografarevialepindaro2016 Workshop di Fotografia I Corso di Rilevamento dell'Architettura prof. Antonella SALUCCI I a.a. 2016/2017 I

Figure 4. Pescara University District. \#theinbetween, Photographic survey project. Available online: http://www.allievivialepindaro.wordpress.com; a mobile-photography contest for Instagram @allievivialepindaro, \#fotografarevialeindaro2016. 
MOTTO: punti di vista

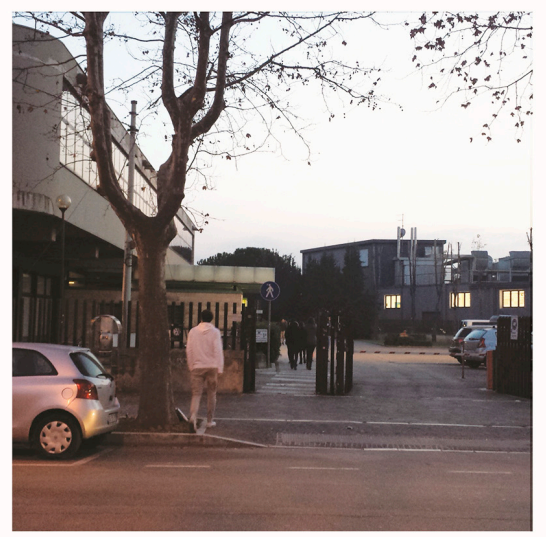

1 - dinamico

3 - profondità

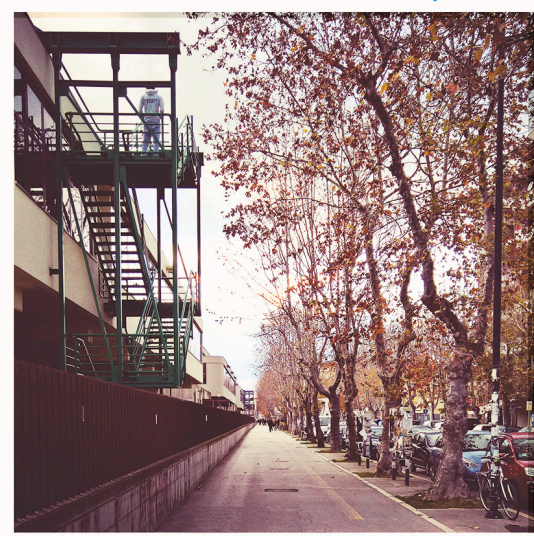

I Alessandro MANZARA

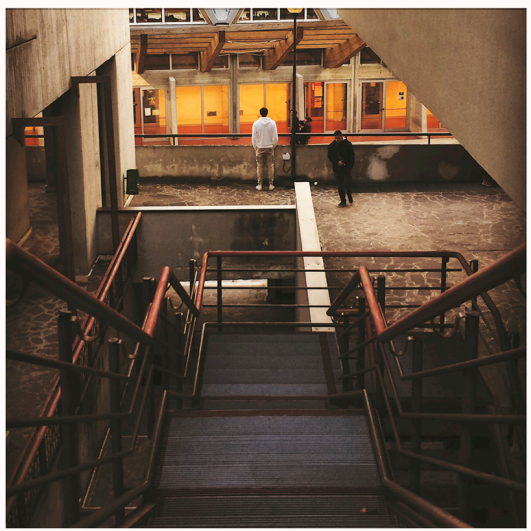

2 - linee spezzate

4 - riflesso

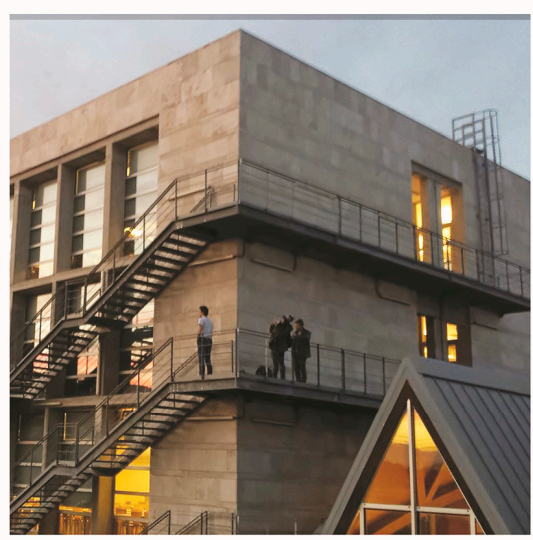

3. CONTEST FOTOGRAFICO THEINBETWEEN 2016/2017 | \#fotografarevialepindaro2016

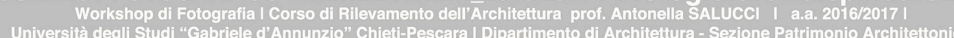

Figure 5. Pescara University District. \#theinbetween, Photographic survey project. Available online: http://www.allievivialepindaro.wordpress.com; a mobile-photography contest for Instagram @allievivialepindaro, tag \#fotografarevialeindaro2016.

A visual narrative of everyday places, the places that are frequented by students, related to university activity, throughout the day.

The seminar, which results in series of compositions related to poetics of storytelling, reconstructs some of the phases of the daily experience of the authors/students/architects/ photographers of the Pescara School of Architecture.

The investigation is conducted using the mobile-photography technique, and is therefore quick, instinctive, spontaneous, and creative.

A way to survey and represent collective spaces - of movement, rest, fun, meeting, socializing, waiting, and relaxing - through which it is possible to retrace various singular dynamics observed and fixed on the digital sensor from a privileged point of view.

The results of the survey of these spaces of movement, make up a fascinating visual system, inside which there are various recognizable hints of aesthetic inclinations, of cultural attitudes, logistical needs, and student attendance and habits.

From a personal point of view through mobile-photography, students survey the space of the city that they live in and produce an innovative piece of visual work that tells us about a dialogue or an interaction, that is attributed to a sort of conceptual work that is put forward again like in a visual atlas, the significant blocks of the everyday life of the Architecture students. 
As part of our survey, we aim to creatively explore a collective space by experimenting with the capture of a temporal fragment, the testimony of collective living, with an everyday tool like the smart-phone.

With the objective of detecting and representing, through taking photographs of various urban spaces, the student is required to design and think of keywords and photographic images - a sort of story-telling - that are representative of the personal way of 'living' Viale Pindaro, the avenue adjacent to the university buildings in Pescara.

This is in order to portray various aspects connected to the everyday use of a number of connective spaces 'between' the environments where studying activities take place (Figure 3a,b).

Since every student has access to a smartphone, this tool for taking photographs has been chosen as it provides a level playing field to compare the work.

The technique of taking photos with an iPhone is based solely on attitudes, sensitivity, and perceptual aspects; it allows you to make notes and observations with images in complete freedom; to experiment with 'visions', freeing ourselves from a traditional approach to photography in favor of greater creativity and perceptual openness [8].

This position allows those who are starting to observe architecture to get away from any technical or technological constraints, in favor of a better understanding and interpretation of the architectural subject.

Choosing the mobile-photography, the smart phone, to make edits, do retouches, and share the images from the survey and documentation in an area of study is an unconventional yet widespread approach to digital photography.

In traditional digital shooting techniques, the photograph is mainly processed once it has already been taken, in so-called 'post-production'.

This is where the crude, raw NEF/RAW file is taken and the digital negative is transformed into a photograph.

Photographing with the smart phone allows and forces preliminary decisions to be made at the same time.

A type of 'constraint' that facilitates the assessment of the scenario ahead, and invites the observer-the student architect, researcher, photographer, iPhoneographer-to prefigure the final result before taking it.

Mobile-photography is a mode of representation that creates freedom of choice and, above all, allows a free and creative approach to research. Stimuli, intuitive conditioning that simultaneously allows the personal photographic model to be composed in that articulated and instinctive interaction between observation, comprehension, imagination, and intention.

Detect and represent, through some photographic images, the places that are frequented by student-architects, related to university activity, throughout the day.

The students are required to design a four-step sequence-combined with key words that make up the motto of the project - that is representative of their personal 'way of life' on viale Pindaro: planning a story that gives meaning to the images; take four 1:1 format pictures that include an avatar subject in a white t-shirt, taken from behind; identify four keywords that create a motto; share on Instagram, tag \#fotografarevialepindaro (Figure 5).

The workshop in the form of the photographic contest has allowed an unpublished and interesting view of the urban landscape that characterizes the university district of Polo Pindaro, which is made up of an architectural matter that we could define as various and sometimes conflicting. Peculiar activities of making Photography and, more generally, of Representing.

\section{Post Scriptum - The Light of Pescara}

This is not a photographic story. It is difficult to capture the elusive perceptive stimuli that derive from the light of Pescara. It is an inventory of visual fragments. A demonstration of the need to create a visual experience based on the city's spectacular light. They are freeze-frame images, governed by slowness and suspension. They are pictures taken "from the window". Visual notes sketched in a notebook by an observer who is constantly on the move. Fragments of urban spaces collected for 
nearly two decades without any specific educational intention. A creative exploration that only now begins to take shape and direction. An open, visual project, of which this writing consists of the number zero. Pescara is a complex and contradictory city. Pescara is ephemeral, relentless. Pescara is attractive at night. Pescara is sunny in the day. Pescara is complex. Difficult to get to know. Hard to capture. Pescara is above all an atmosphere, a light, a mood. Pescara is the diffused air of a blue, green, salty powder. Deep blue, strong green, yellow. Ochre. Pescara is a city of water. Pescara is liquid and elusive. Pescara. The Adriatic. Its visual impact stuns and disorients you right from the early hours of the day. Wonder ...

Pescara. Day. Sea light dazzles, confuses, and eliminates the value of chromatic effects on shape. Pescara. Night. The light at night enhances and draws attention to the movement of human artifice by bringing an intimate, underground performance to the scene. I absolutely have to take photos of Pescara! How can we measure the light? How can we investigate complexity? How can we get in touch with the urban space and capture its essence? The work around the light in each space is made of familiarity and profound knowledge. It commands respect. I watch. I walk. I wait. I try. Nikon D700. Tripod. I balance it. I carefully expose it. I frame it. I take the shot. I capture the evening light, not the deep darkness, but that which distinguishes the light from the sky. Pescara is a city made up of visual layers. It is perfect for current digital light and colour capture styles. I do not record in a ruthless manner, I investigate. I memorize freely. I allow myself to change my mind. I acquire an overabundance of 'raw' information. I border on new creative registers made up of levels. I gather complex information. Free to operate preliminarily or in post-production. Absolute chromatic fidelity, a variety of outcomes. I prepare for an open image.

I walk. I wait. I think. I digest. I know. I measure. I use the 'raw' format. I recapture the nighttime light. The river, the architecture, the city. The light is always altered, surreal. Pescara is a city made up of visual layers. I have endless possibilities. I reflect. I return the raw file, just as I took it. The extraordinary and elusive Pescara [9-11] (Figure 6).

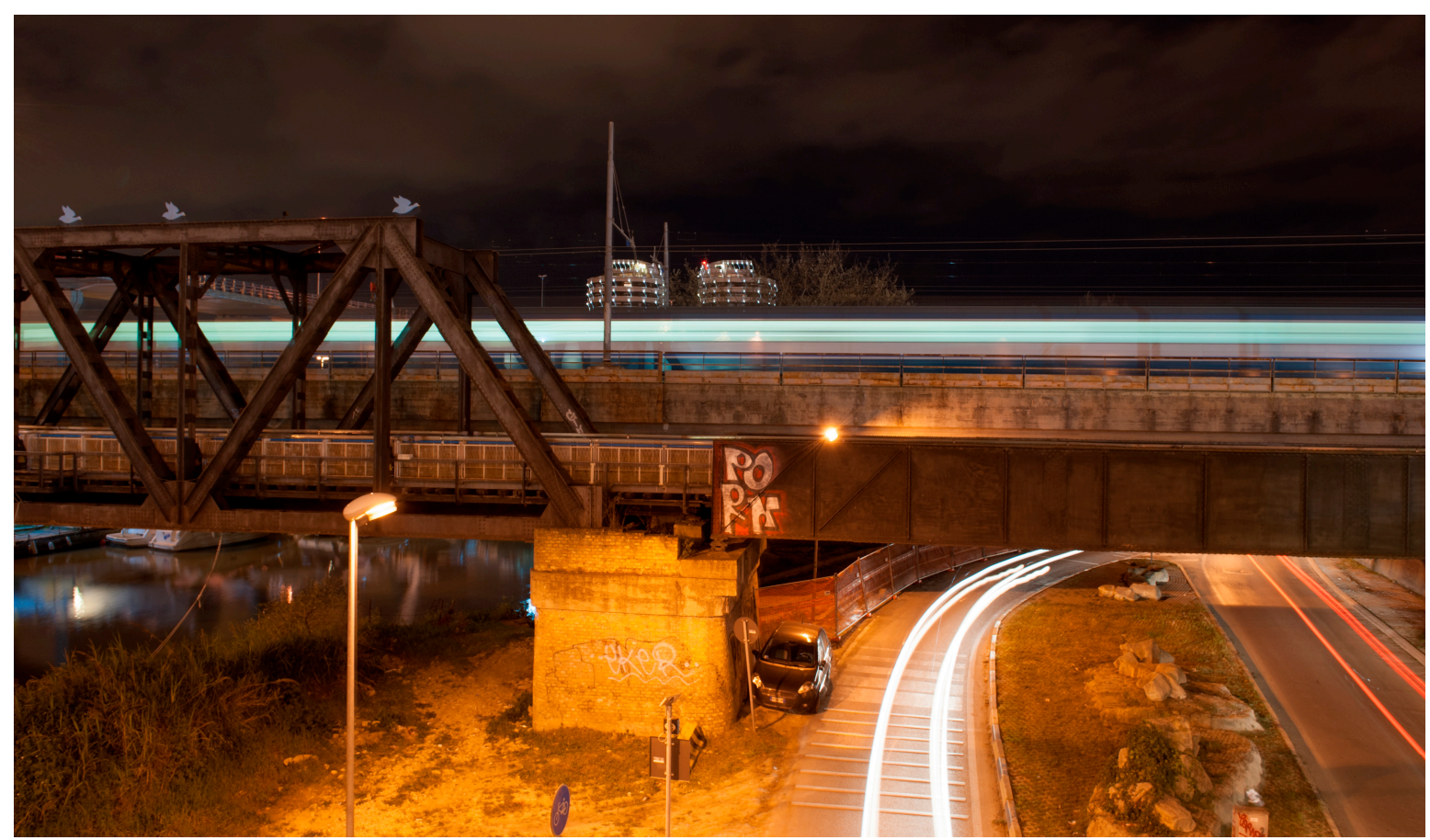

Figure 6. Pescara. Evening. The bridge, the towers. (Photograph by Antonella Salucci).

Conflicts of Interest: The authors declare no conflicts of interest. 


\section{References}

1. Sottsass, E. Foto dal Finestrino; Biblioteca minima, n 38; Adelphi Edizioni: Milano, Italy, 2012; p. 51.

2. MiBACT, 2017. Stati Generali della Fotografia. Conservazione e Valorizzazione del Patrimonio. Memoria, Identità, Futuro. Available online: http://www.beniculturali.it/mibac/export/MiBAC/sito-MiBAC/Contenuti/ MibacUnif/Comunicati/visualizza_asset.html_1766819048.html (accessed on 11 September 2017).

3. Fondazione Symbola, Io Sono Cultura. Rapporto 2017. Available online: http://www.symbola.net/html/ article/iosonocultura17ricerca (accessed on 11 September 2017).

4. Sacchi, L. La costa abruzzese. In La Riva Perduta Plan for Monitoring and Redeveloping the Italian Coastal Areas. PRIN 2002-2004; De Rubertis, R., Ed.; Officina Edizioni: Rome, Italy, 2005; pp. 154-181.

5. Alici, A. Le vite della città. In Pescara, Forma Identità e Memoria Della città fra XIX e XX Secolo; Alici, A., Pozzi, C., Eds.; Carsa Edizioni: Pescara, Italy, 2004; p. 24.

6. Clementi, A. Pescara città. In La città nuova Italia-Y-26 Invito a VEMA; Catalogue of the Venice Biennale. 10th International Architecture Exhibition; Purini, F., Marzot, N., Sacchi, L., Eds.; Editrice Compositori: Bologna, Italy, 2006; p. 303.

7. Spalletti, E. Interview with Ettore Spalletti. In Il Giornale dei Musei d'Abruzzo n.4/2006; MU6, Pescara, Italy, 2006; p. 8. Available online: http://www.rivistamu6.it/pdf/MU6_04.pdf (accessed on 11 September 2017).

8. Calabrese, S. Fotografare con l'iPhone; Logos Edizioni: Modena, Italy, 2011.

9. Rosselli, P. Sandwich Digitale. La vita Segreta Dell'Immagine Fotografica; Quodlibet: Macerata, Italy, 2009.

10. Salucci, A. The Urban Space of the Ephemeral Heritage. Celebrations of Big Shoulder-Borne Processional Structures. In Proceedings of the XIV International Forum 'Le Vie dei Mercanti. World Heritage and Degradation. Smart Design, Planning and Technologies”, Naples-Capri, Italy, 2016; La Scuola di Pitagora: Naples, Italy, 2016.

11. Salucci, A. Pescara 'Night and Day'. Un'atmosfera, una luce, una visione/An atmosphere, a light, a vision. In Disegnare Pescara Nell'esperienza Didattica. "Da Piazza Salotto a Times Square". Yearbook-Rilevamento Dell'Architettura 2014/2015; Maurizio Unali, M., Ed.; Gangemi Editore: Rome, Italy, 2015; p. 152.

(C) 2017 by the author. Licensee MDPI, Basel, Switzerland. This article is an open access article distributed under the terms and conditions of the Creative Commons Attribution (CC BY) license (http://creativecommons.org/licenses/by/4.0/). 